\title{
Editorial
}

\section{"Doctor I have to take 54 tablets a day and also injections"}

\author{
Journal of the Ceylon College of Physicians, 2018, 49, 1
}

This is not an infrequent complaint from patients these days. This type of polypharmacy seems to be the trend now with advances made in the science of medicine. What should we expect with modern medicine and its advances? Just one drug that cures the disease or controls the metabolic derangement or a multitude of drugs acting on each enzyme that is involved for example in glucose metabolism or blood pressure regulation!

Below are two prescriptions from real patients.

Patient 1. 39 years old and five years after pituitary tumour surgery and now has cirrhosis of the liver Actrapid noon, Mixtard morning, Lantus night, Metformin SR-500×3, Acarbose-50×2, Sitagliptin 100, Gliclazide 80 and 160, Desmopressin 25×2, Cortisone 2.5,2.5,5mg, Atorvastatin 5mg, Irbesartan 75mg, Pantoprazole $40 \mathrm{mg}$ all for 2 months

\section{Patient 2. 75 years with diabetes and sensory neuropathy}

Sitagliptin 50mg $\times 2$, Metformin SR 1000×2, Gliclazide MR 60×2, Empagliflozin 10mg, Lantus Insulin, Cardiprin 100 , Vitamin C $200 \times 2$, Amitryptiline 10mg, Duloxetine $30 \mathrm{mg}$, Pregabalin $75,50,75 \mathrm{mg}$, Atorva $10 \mathrm{mg}$, Clopidogrel $75 \mathrm{mg}$, Diltiazem 90mg, Neurobion 1, Analep cream all for 3 months.

There is trial evidence for each drug above and is approved for use. But no one has tested all these in one patient for an adequate length of time. So we have no knowledge how all these drugs work together in the human body and what complications they will result in in the long run. As in patient 2 who is 75 years old what effects will all these drugs have on his liver, kidneys and the brain? A combination of amitryptiline, duloxetine and pregabalin, all three with effects on the central nervous system is more likely to have negative effects on an ageing brain than the benefits accrued. I hope we can tide this trend of polypharmacy. What would be the quality of life of these patients with nausea and poor appetite resulting from swallowing so many tablets and the cost to them? So if our patients are to take so many tablets is it a sign of progress of medicine or its failure?

This issue will be the last issue of me being the editor and I will be stepping down after completing two terms. Publishing a journal is easy with modern technology being at hand but at the same time no journal can be published if there are no articles to go into it. With so many journals mushrooming all over and with easy access, having adequate numbers of articles is the major obstacle for the smooth continued publication of regular issues. I hope this trend will change with the new editors in charge and I wish them all the best.

\section{Saman B Gunatilake}

Co Editor

JCCP 